\title{
Ethanol Extract of Gardenia augusta (L.) Merr. Flowers Produces Sleep Improvement in Rat Model
}

\author{
Kusnandar Anggadiredja*, I Ketut Adnyana, Dewi Safitri, Siti Farah Rahmawati, Tomi Hendrayana
}

Kusnandar Anggadiredja*, I Ketut Adnyana, Dewi Safitri, Siti Farah Rahmawati, Tomi Hendrayana

Department of Pharmacology and Clinical Pharmacy, School of Pharmacy Institut Teknologi Bandung, Jl. Ganesa 10 Bandung 40132, INDONESIA.

\section{Correspondence}

\section{Kusnandar Anggadiredja}

Department of Pharmacology and Clinical Pharmacy, School of Pharmacy Institut Teknologi Bandung, Jl. Ganesa 10 Bandung 40132, INDONESIA.

Phone no: +62 22 2504852;

E-mail: kunay.kusnandar@gmail.com

History

- Submission Date: 10-09-2019;

- Review completed: 04-10-2019;

- Accepted Date: 04-10-2019.

DOI : 10.5530/pj.2019.11.224

Article Available online http://www.phcogj.com/v11/i6s

\section{Copyright}

(C) 2019 Phcogj.Com. This is an openaccess article distributed under the terms of the Creative Commons Attribution 4.0 International license.

\section{ABSTRACT}

Introduction: Sleep disorder may have detrimental consequences on health and one of the treatments is the use of hypnotics. Unfortunately, hypnotics treatment may also be accompanied by side effects and lead to dependence. The present study aimed to investigate the sleep improving effects of ethanol extract of Gardenia augusta (L.) Merr. flowers in rat model. Methods: Rats were assigned into group receiving the extract (at 0.9 or $1.8 \mathrm{~g} / \mathrm{kg}$ ), the reference drug crocetin (at $0.9 \mathrm{mg} / \mathrm{kg}$ ) or vehicle, once a day orally for 15 days. Results: Tested on day 1 and 14 of treatment, the rats receiving $1.8 \mathrm{~g} / \mathrm{kg}$ of the extract showed improvements in sleep latency, sleep duration, sleep efficiency, wake episodes, and sleep cycle, which were significantly different from crocetin. Furthermore, tested on day 2 and 15 of treatment, the rats treated with $1.8 \mathrm{~g} / \mathrm{kg}$ extract demonstrated superior sedative rating scale compared to crocetin. Conclusions: Results of the present study indicates the potential of Gardenia augusta (L.) Merr. flower extract to be used as an adjunct treatment for sleep disorder.

Key words: Sleep, Improvement, Gardenia augusta (L.) Merr., Flowers, Rats.

\section{INTRODUCTION}

Sleep disorder has become a global issue that has to be taken into consideration seriously. The World Health Organization has reported that in Asian and African regions $16.9 \%$ adults had serious sleep problem with the increase in prevalence ranged from 3.9\% (Indonesia and Kenya) to $40 \%$ (Bangladesh). In addition, from the eight surveyed countries, the problem was more prevalent in women and elderly than in men. ${ }^{1}$

One of the most prevalent sleep disorders is insomnia, which is characterized by disturbed sleep onset and sleep maintenance, or poor quality sleep, rendering the impairment of functioning in the following days, with the possible ensuing psychological distress. ${ }^{2,3}$ The first treatment of sleep disorder or decreased quality sleep should be nonpharmacological measures. However, when this method does not work, pharmacological treatment may be needed which include the use of hypnotic drugs. Unfortunately, the use of this class of drug poses the users to the risk of dependence and its detrimental sequelae. Early works have been carried out to test the effects of supplements in an effort to prevent the risk. Thus, Attelle and co-workers ${ }^{4}$ have suggested the use of herbals and amino acids. Corroborating this suggestion, Ziegler and collaborators $^{5}$ as well as Yamadera and colleagues ${ }^{6}$ have demonstrated sleep ameliorating activity of valerian and glycine. Additionally, there has been a thorough review that indicates the potential of herbals to treat sleep disorder, with the GABA-ergic system as the proposed target brain substrate. ${ }^{7}$

One of the medicinal plants suggested to have sleep-improving activity is Gardenia augusta. ${ }^{8,9}$ Gardenia augusta, which belongs to the family of Rubiaceae, originated in Asia. The plant is called zhi zhi in China and kuchinashi in Japan. In both countries the yellow flowers are used as dye for cloth and food. Meanwhile, the white, large flowers are highly fragrant..$^{10}$ The plant has been shown to contain several chemical constituents, including crocetin, crocin, ${ }^{11}$ geniposide and genipin. ${ }^{12}$ Being an oriental medicine, Gardenia is used to treat inflammation, jaundice, headache, edema, fever, hepatic disorders, and hypertension. ${ }^{13}$

Several preclinical studies have further demonstrated the pharmacological properties of active ingredients contained in Gardenia. Crocin and crocetin were shown to have pancreatic lipase inhibiting activity. ${ }^{14}$ Crocin was also shown to have antioxidant property. ${ }^{15,16}$ Geniposide was found to have antiangiogenic and neuroprotective activities. ${ }^{17,18}$ Geniposide and other ingredient isolated from the fruit, genipin, also demonstrated anti-inflammatory property. ${ }^{19}$

In the present study, we investigated the sleepimproving effect of ethanol extract of the flowers of Gardenia augusta (L.) Merr. The possible effect was compared to crocetin, a secondary metabolite contained in Gardenia, previously demonstrated to have ameliorating effect on sleep disorder.

\section{MATERIALS AND METHODS}

\section{Plant materials and drugs}

Crude drug was prepared from the plant Gardenia augusta (L.) Merr. collected from Manoko botanical garden in the Northern part of Bandung Indonesia The plant was determined for identification in Herbarium Bandungense, School of Life Sciences and Technology, Institut Teknologi Bandung. Dried ground raw materials were refluxed with $96 \%$ 
ethanol. The extract obtained was then concentrated using rotary evaporator (Buchi, Flawil Switzerland). The concentrated extract was prepared to make test doses of 0.9 and $1.8 \mathrm{~g} / \mathrm{kg}$. Crocetin was purchased from Sigma. All the substances were dispersed in $0.3 \%$ Sodium-CMC and were given orally at $0.1 \mathrm{ml} / 100 \mathrm{~kg}$ of body weight, once a day for 15 days.

\section{Animals}

Male Wistar rats (150-200 g) supplied by Animal Laboratory of School of Pharmacy Institut Teknologi Bandung were used. The animals were acclimatized for one week before the experiments. They were kept at constant ambient temperature of $25^{\circ} \mathrm{C}$ under 12-h light/dark cycle with free access to food and water except during observations. The rats were assigned into four groups of 6 each, treated with $0.3 \%$ Sodium-CMC, $0.9 \mathrm{~g} / \mathrm{kg}$ extract, $1.8 \mathrm{~g} / \mathrm{kg}$ extract, and $0.9 \mathrm{mg} / \mathrm{kg}$ crocetin, respectively. Procedures for animal handling have been approved by the committee of laboratory animal use and care, Faculty of Medicine Padjadjaran University, Bandung, Indonesia (Certificate of Approval No 07/UN6. $\mathrm{KEP} / \mathrm{EC} / 2018$ ), which is in line with the principle of replacement, refinement and reduction of animal use in research.

\section{Sleep latency}

Sleep latency was defined as the period between test substance administration and the time the rats started to fall asleep. The latency was determined on day 1 and 14 of treatment, confirmed with thermal camera (FLIR E5) to observe changes in brain as well as dorsal temperatures.

\section{Sleep duration}

Sleep duration was defined as duration of sleep after administration of test substance. The measurement, performed on day 1 and 14 of treatment, was confirmed by using thermal camera to observe changes in brain and dorsal temperatures.

\section{Sleep efficiency}

The sleep efficiency was calculated using data of sleep duration and latency, using the following formula,

Sleep efficiency $(\%)=$ Sleep duration / (Sleep latency + Sleep duration)

\section{Wake episodes}

Wake episode was defined as the amount of waking during sleeping period. Recorded on day 1 and 14 of treatment, this parameter was confirmed using thermal camera to observe changes in brain as well as dorsal temperatures.

\section{Sleep cycle}

Sleep cycle was determined using thermal camera on day 1 and 14 of treatment. The cycle was defined as a condition in which alteration between decrease (NREM) and increase (REM) in brain and dorsal temperatures took place.

\section{Sedative effect}

The sedative effect, observed on day 2 and 15 of treatment, was measured based on assessment on sedation rating scale. The rating measured the scale between 0 to 5 , with $0=$ sleeping characterized by eyes fully closed, relaxed body, $1=$ severe sedation marked by closed eyes, loss of righting reflex, 2 =head partly or completely down, eyes partly closed, flat posture, no spontaneous movement, $3=$ eyes partially closed, head somewhat down, movement disturbance, abnormal posture, limbs partially used, dragging and stumble, $4=$ eyes fully open, head up, no or limited movement, rearing or grooming, normal posture, $5=$ active movement, rearing, head movement or grooming.

\section{Statistical analysis}

Experimental data are presented as means + SD. Significance of difference between groups was determined using One-way ANOVA for the comparison of sleep quality among treatment groups, paired student t-test for comparing sleep quality observed at day 1 and 14, and Kruskal-Wallis to compare data represented in sedation rating scale. A difference was considered significant at $p<0.05$.

\section{RESULTS}

\section{Sleep latency}

As shown in Figure 1, the sleep latencies on day 1 for group of mice receiving 0.9 and $1.8 \mathrm{~g} / \mathrm{kg}$ were $138.83 \pm 45.04 \mathrm{mins}$ and $87.0 \pm 20.43$ mins, respectively which were significantly different from that of the vehicle-treated group that was $201.33 \pm 25.46(p<0.05)$. On day 14 the latencies were $136.67 \pm 38.69$ and $80.83 \pm 27.46$ mins, respectively, significantly different $(p<0.05)$ from the value of the vehicle-treated group which was $197.50 \pm 33.73$ mins. While the latency observed in group receiving $0.9 \mathrm{~g} / \mathrm{kg}$ extract was not significantly different from that treated with the reference drug crocetin, the sleep latency in group receiving test substance at $1.8 \mathrm{~g} / \mathrm{kg}$ was significantly shorter compared to that in crocetin group.

\section{Sleep duration}

Results on the effect of the extract on sleep duration are shown in Figure 2. On day 1, the duration in groups receiving 0.9 and $1.8 \mathrm{~g} / \mathrm{kg}$ extract were $332.33 \pm 39.83$ mins and $374.67 \pm 20.43$ mins, respectively which were significantly different compared to that of vehicle-treated group $(p<0.05)$ with the duration of $252.33 \pm 25.19$ mins. Meanwhile, on day 14 , the respective durations of groups treated with 0.9 and 1.8 $\mathrm{g} / \mathrm{kg}$ extract were $332.50 \pm 39.72 \mathrm{mins}$ and $387.0 \pm 28.06 \mathrm{mins}$, which were significantly different from that of control of $276.67 \pm 22.52$ mins. Sleep duration in group receiving $0.9 \mathrm{~g} / \mathrm{kg}$ extract was comparable to that in group receiving the reference substance crocetin, however the duration observed in $1.8 \mathrm{~g} / \mathrm{kg}$ extract-treated group was significantly longer than that of the crocetin group.

\section{Sleep efficiency}

Figure 3 demonstrates the results on sleep efficiency. As the figure shows, on day 1 , the efficiencies in the groups treated with 0.9 and $1.8 \mathrm{~g} / \mathrm{kg}$ extract were $70.74 \pm 8.05 \%$ and $81.11 \pm 4.13 \%$, respectively,

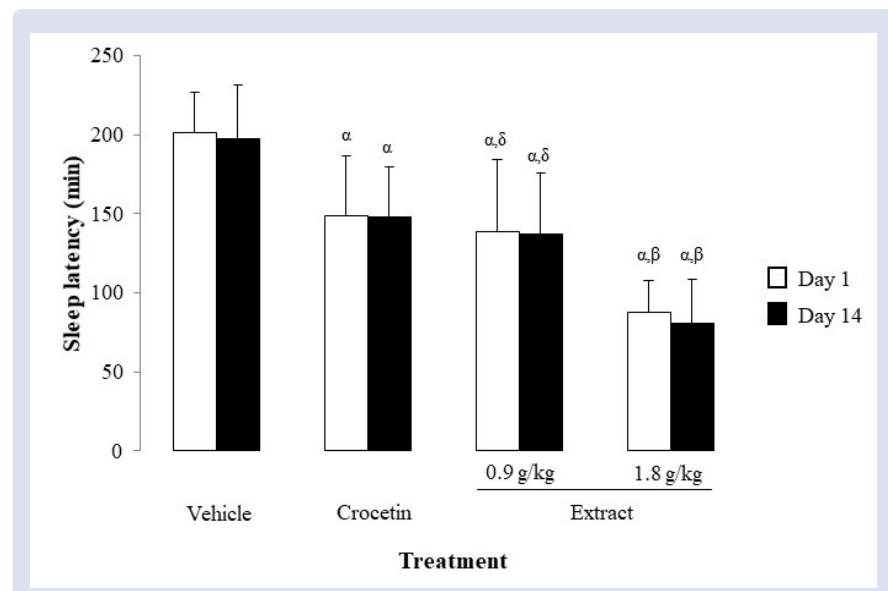

Figure 1: Effects of ethanol extract of Gardenia augusta (L.) Merr. leaves on sleep latency in rats. The period between test substance administration, orally, and the time the rats started to fall asleep was recorded. Data represent the average+SD of sleep latency, collected on days 1 and 14 of treatment, with 6 rats per group. ${ }^{a, \beta, \delta} \mathrm{p}<0.05$ compared with vehicle, crocetin $(0.9 \mathrm{mg} / \mathrm{kg})$, and $1.8 \mathrm{~g} / \mathrm{kg}$ extract, respectively. 


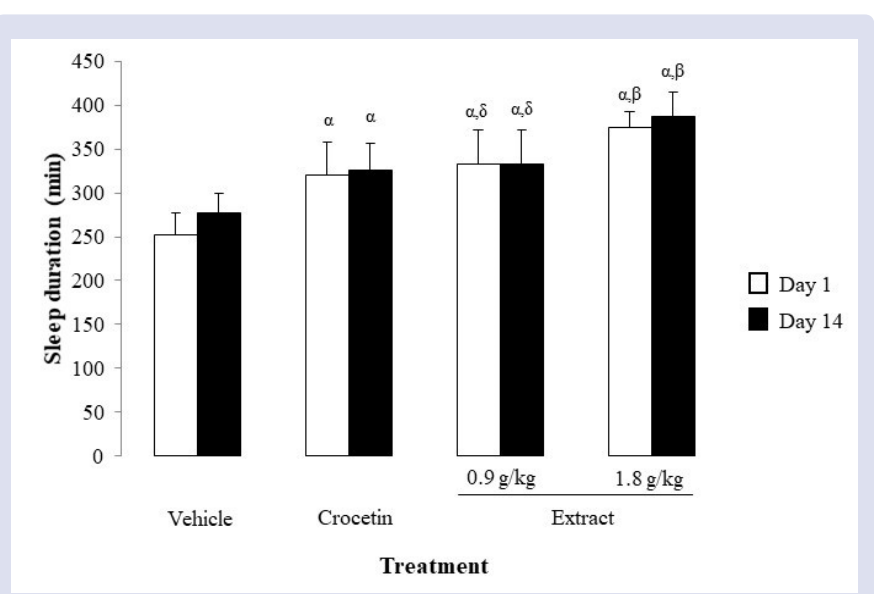

Figure 2: Effects of ethanol extract of Gardenia augusta (L.) Merr. leaves on sleep duration in rats. The duration of sleep after administration of test substance, orally, was recorded. Data represent the average+SD of sleep duration, collected on days 1 and 14 of treatment, with 6 rats per group. ${ }^{a, \beta, \delta} \mathrm{p}<0.05$ compared with vehicle, crocetin $(0.9 \mathrm{mg} / \mathrm{kg})$, and $1.8 \mathrm{~g} /$ kg extract, respectively.

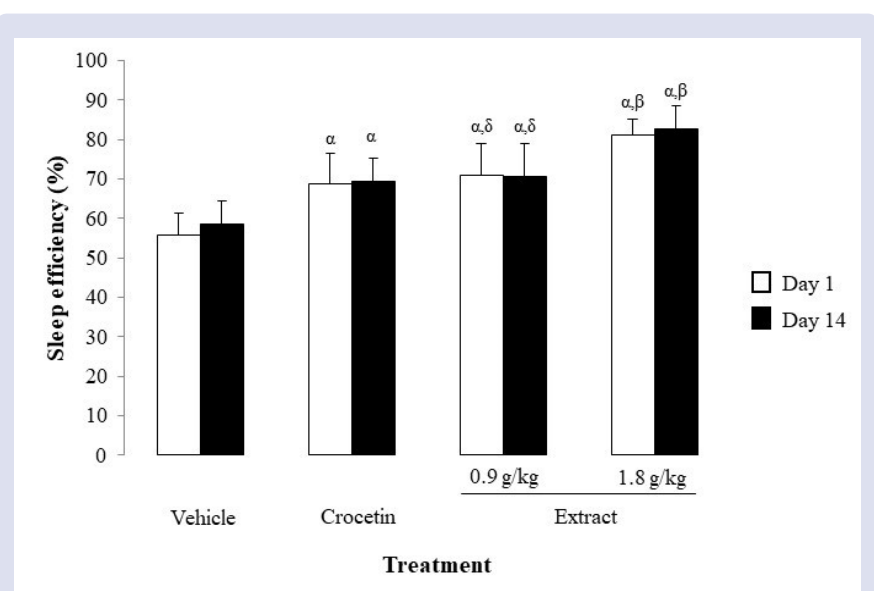

Figure 3: Effects of ethanol extract of Gardenia augusta (L.) Merr. leaves on sleep efficiency in rats. The efficiency was worked out by dividing sleep duration by the sum of sleep latency and sleep duration. Data represent the average+SD of sleep efficiency, with 6 rats per group. ${ }^{a, \beta, \delta} p<0.05$ compared with vehicle, crocetin $(0.9 \mathrm{mg} / \mathrm{kg})$, and $1.8 \mathrm{~g} / \mathrm{kg}$ extract, respectively.

significantly different $(p<0.05)$ from that in group treated with vehicle whose value was $55.62 \pm 5.56 \%$. On day 14 , the respective efficiencies of the groups were $70.86 \pm 8.18 \%$ and $82.75 \pm 5.82 \%$, significantly higher than $58,47 \pm 6.00 \%$ of the vehicle-treated group $(p<0.05)$. While the efficiency shown by the $0.9 \mathrm{~g} / \mathrm{kg}$ extract-treated group was comparable to that of the reference substance crocetin, the sleep efficiency in group treated with $1.8 \mathrm{~g} / \mathrm{kg}$ extract was significantly higher than that of $0.9 \mathrm{~g} /$ $\mathrm{kg}$ extract or crocetin-treated group.

\section{Wake episodes}

Results on the wake episodes are described in Figure 4. On day 1 the episodes in groups receiving 0.9 and $1.8 \mathrm{~g} / \mathrm{kg}$ extract were $7.17 \pm 1.69$ and $4.20 \pm 1.82$, respectively, significantly lower $(p<0.05)$ compared to that in vehicle-treated group which had the value of $12.33 \pm 2.73$. On day 14 the episodes in groups receiving 0.9 and $1.8 \mathrm{~g} / \mathrm{kg}$ extract were $6.85 \pm 2.02$ and $3.48 \pm 1.43$, respectively, which were also significantly lower compared to that in vehicle-treated group with the value of 11.50 \pm 2.47 . The wake episode in group treated with $0.9 \mathrm{~g} / \mathrm{kg}$ extract was comparable to that observed in group receiving the reference substance crocetin (with respective values of $7.27 \pm 2.86$ and $7.30 \pm 1.76$ on day
1 and 14). Meanwhile, the figure was significantly lower $(p<0.05)$ in group treated with $1.8 \mathrm{~g} / \mathrm{kg}$ extract compared to crocetin-treated group.

\section{Sleep cycle}

Figure 5 depicts the results on the number of sleeping cycle. It was shown that the cycles were significantly lower $(p<0.05)$ in groups treated with the test doses of the extract as well as the reference substance crocetin. On day 1 the number of cycles in group treated with 0.9 and $1.8 \mathrm{~g} / \mathrm{kg}$ extract and vehicle-treated group were $4 \pm 0.63$, $4.5 \pm 1.05$, and $6.33 \pm 0.82$, respectively. Meanwhile, the respective figures on day 14 were $4 \pm 0.63,3.67 \pm 1.51$, and $6 \pm 0.89$. No significant difference was observed in the number of cycle among the group treated with extracts and crocetin.

\section{Sedative effect}

Results on the sedation rating scale are shown in Figure 6. Significant differences in sedation rating scale among treatment groups were observed both on days 2 and 15 (respective Kruskal-Wallis were 14.94 and 15.25 , and both days had $p<0.05$ ). While the score in group

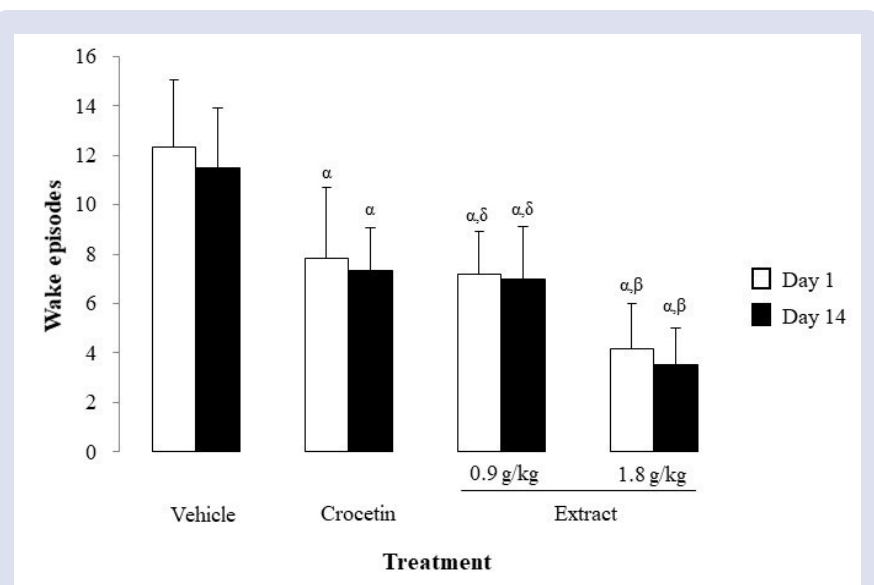

Figure 4: Effects of ethanol extract of Gardenia augusta (L.) Merr. leaves on wakeup episodes in rats. The amount of waking during sleeping was recorded. Data represent the average+SD of sleep duration, collected on days 1 and 14 of treatment, with 6 rats per group. ${ }^{a, \beta, \delta} p<0.05$ compared with vehicle, crocetin $(0.9 \mathrm{mg} / \mathrm{kg})$, and $1.8 \mathrm{~g} / \mathrm{kg}$ extract, respectively.

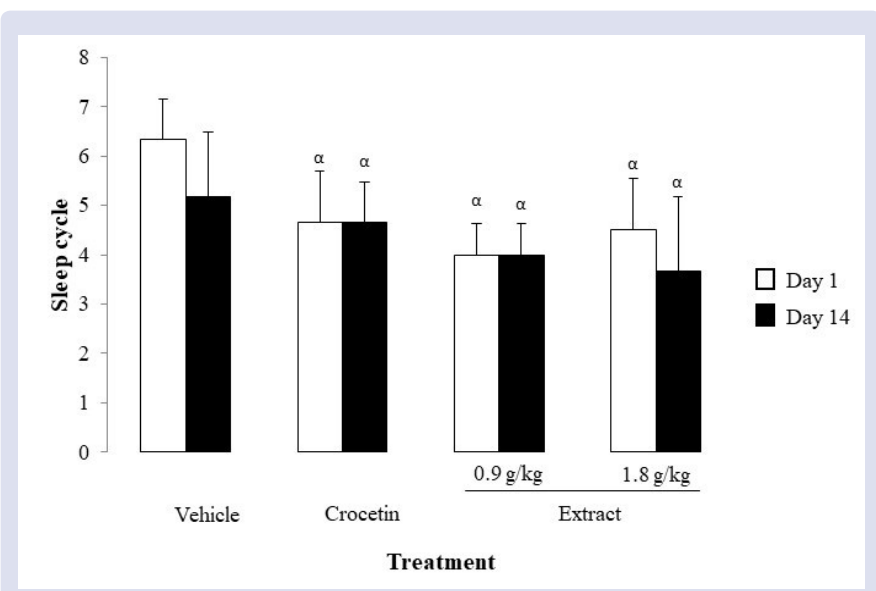

Figure 5: Effects of ethanol extract of Gardenia augusta (L.) Merr. leaves on sleeping cycles in rats. The alteration between decrease in brain and dorsal temperatures (NREM) and their increase (REM) was recorded. Data represent the average+SD of sleep duration, collected on days 1 and 14 of treatment, with 6 rats per group. ${ }^{a} \mathrm{p}<0.05$ compared with vehicle. 


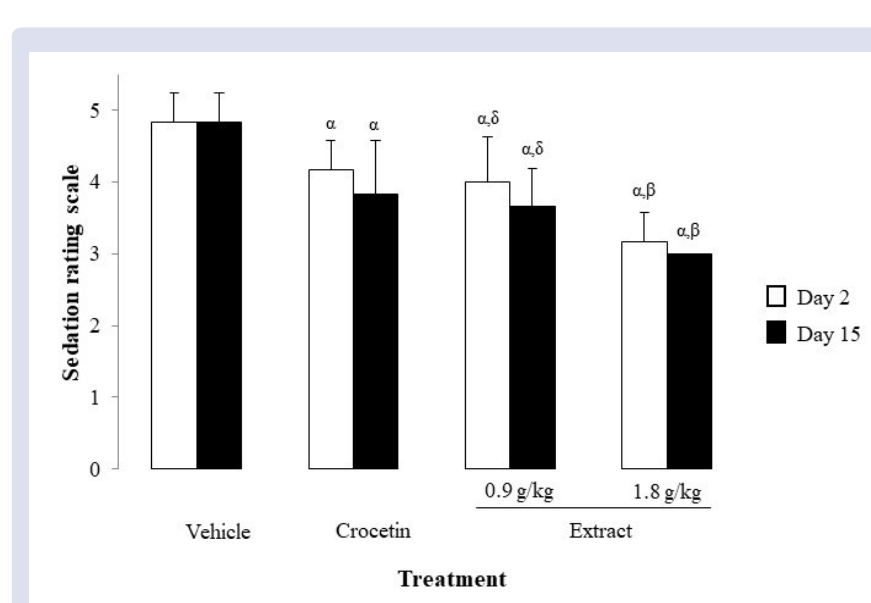

Figure 6: Effects of ethanol extract of Gardenia augusta (L.) Merr. leaves on sedation rating scales in rats. The scales, based on the level of behavior suppression, ranging from 0 (highly suppressed) to 5 (normal behavior) were recorded for $2 \mathrm{mins}$. Data represent the average+SD of the scale, collected on days 2 and 15 of treatment, with 6 rats per group. $a, \beta, \delta p<0.05$ compared with vehicle, crocetin $(0.9 \mathrm{mg} / \mathrm{kg})$, and $1.8 \mathrm{~g} / \mathrm{kg}$ extract, respectively.

receiving $0.9 \mathrm{~g} / \mathrm{kg}$ extract was not significantly different from that in crocetin-treated group, the score in group receiving $1.8 \mathrm{~g} / \mathrm{kg}$ extract was significantly lower compared to the crocetin group.

\section{DISCUSSION}

The present study investigated the effect of flower extract of the plant Gardenia augusta (L.) Merr. in rat model. Earlier studies have demonstrated the components of this plant contained metabolite showing the activity to improve the quality of sleep. While flowers are often regarded as waste after they fall to the ground, or used as a decorative component, mostly the plant part studied for the biological activities was the fruits. ${ }^{20-24}$ To the best of our knowledge, the present study was the first one which focused on investigating the effect of flower extract of the plant on sleep improvement.

The extract was shown to dose-dependently improve the sleep quality with the highest dose of $1.8 \mathrm{~g} / \mathrm{kg}$ being superior compared to the reference drug crocetin. The test doses of 0.9 and $1.8 \mathrm{mg} / \mathrm{kg}$ extract were selected based on the result of an unpublished preliminary data that showed potentiating effect Gardenia flower ethanol extract on phenobarbital-induced hypnosis. The characteristic of effect of the flower extract resembled that of crocetin, isolated from the Gardenia fruits. While it has not been confirmed the possible active ingredient responsible for the activity at this stage, judging from the present results, one may suggest that the substance at least in part had the similarity with crocetin, which was used as reference substance in the present study.

We found the effective dose of the flower extracts being somewhat on the high side, as the results showed that the dose of $1.8 \mathrm{~g} / \mathrm{kg}$ had the activity which exceeded that of the reference substance crocetin, given at a dose of as low as $0.9 \mathrm{mg} / \mathrm{kg}$. This finding might be attributable to the content of the active substance. As reported by $\mathrm{Gao}$ and $\mathrm{Zhu}{ }^{25}$ crocin, a substance having crocetin in its core, accumulates during fruit maturation, long after blossoming. Furthermore, pharmacokinetic study of crocin in rats revealed that following administration of crocin, only small amount of crocetin, as metabolite of crocin, was found in the blood. ${ }^{26}$ Results of the work of Gao dan $\mathrm{Zhu}^{25}$ specifically demonstrated that crocetin content escalated over time, peaking at stage 4 of fruit development, and no crocetin content found at stage 1 . In terms the other psychoactive component geniposide, however, its content was almost constant even before fruit development. Earlier study by Choi and co-workers ${ }^{27}$ indicated that geniposide exerted the increase in $\mathrm{Cl}$ influx in neuroblastoma, resembling GABA-ergic activation. Taking this data into consideration, one may further suggest that geniposide could be the component of the extract used in our present study, responsible for the sleep-improving effect, as crocin has been shown to be absent at the flowering stage. Interestingly, however, behavioral study failed to show locomotor-suppressing activity of geniposide. The data, thus, points to the possibility of different component which might be contained in the petal of the Gardenia flower with sleep-improving activity. In this respect, substances as revealed by Zhang and co-workers ${ }^{28}$ in the Gardenia flower could be the potential candidate for the ones with the sleep-improving activity.

Sleeping disorder has been indicated to have adverse consequences economically. Albeit unknown outcome of the untreated insomnia, detrimental health outcomes have been recognized to accompany the sleep disorder that include poor quality of life. ${ }^{29,30} \mathrm{Walsh}^{3}$ has demonstrated that direct costs for the management of insomnia have been estimated to be USD13.9 billion annually, and successful treatment of insomnia has been indicated to be correlated with direct cost savings and improved quality of life. ${ }^{31}$ However, the saving observed from the latter study seemed not so significant, probably due to additional expenses that might arise from the psychoactive nature of most medications for the treatment of sleep disorder. The use of safe and effective plant-derived substances to manage sleep disorder might have additional benefits economically.

Results of the present study did not show potential adverse effects of Gardenia flower extract, even when the extract was administered at the dose of as high as $1.8 \mathrm{~g} / \mathrm{kg}$. No matter how safe the extract seems, however, detailed safety assessment on the extract is required.

\section{CONCLUSION}

The present study demonstrated that the flowers of the plant Gardenia augusta (L.) Merr. has sleep-improving activity, further confirming earlier studies and the practice of using the Gardenia plant as an alternative in treating insomnia. At the moment, it is suggested that high doses of the extract are needed for the activity, however, further studies which could be done to pinpoint the exact component responsible for the activity might corroborate the use of flowers of Gardenia, part of the plant often neglected, to be used to combat sleep disorder.

\section{ACKNOWLEDGEMENT}

This work was supported by the 2017 Research and Community Services Funding Scheme of Institut Teknologi Bandung, Grant No 0375/I1.B04/KU/2017. The authors highly appreciate kind assistance of Ms. Tri Nurdini for the technical works.

\section{CONFLICTS OF INTEREST}

The authors declared no conflicts of interest.

\section{REFERENCES}

1. Stranges S, Tigbe W, Gomez-Olive FX, Thorogood M, Kandala NB. Sleep problems: an emerging global epidemic? Findings from the INDEPTH WHOSAGE study among more than 40,000 older adults from 8 countries across Africa and Asia. Sleep. 2012;35(8):1173-81.

2. Walsh JK, Benca RM, Bonnet M, Buysse DJ, Hauri PJ, Kiley J, et al. Insomnia: assessment and management in primary care. Am Fam Physician. 1999;59(11):3029-38.

3. Walsh JK. Clinical and socioeconomic correlates of insomnia. J Clin Psychiatry. 2004;65(8):13-9.

4. Attelle AS, Xie J, Yuan CS. Treatment of insomnia: an alternative approach Altern Med Rev. 2000;5(3):249-59.

5. Ziegler G, Ploch M, Miettinen-Baumann A, Collet W. Efficacy and tolerability of valerian extract LI 156 compared with oxazepam in the treatment of nonorganic insomnia-a randomized, double-blind, comparative clinical study. Eur J Med Res. 2002;7(11):480-6 
6. Yamadera W, Inagawa K, Chiba S, Bannai M, Takahashi M, Nakayama K. Glycine ingestion improves subjective sleep quality in human volunteers, correlating with polysomnographic changes. Sleep Biol Rhythm. 2007;5(2):126-31.

7. Shi Y, Dong JW, Zhao JH, Tang LN, Zhang JJ. Herbal insomnia medications that target GABAergic systems: A review of the psychopharmacological evidence. Curr Neuropharmacol. 2014;12(3):289-302.

8. Toriizuka K, Kamiki H, Ohmura NY. Fujii M, Hori Y, Fukumura M, et al. Anxiolytic effect of Gardeniae Fructus-extract containing active ingredient from Kamishoyosan (KSS), a Japanese traditional Kampo medicine. Life Sci. 2005;77(24):3010-20.

9. Kuratsune H, Umigai N, Takeno R, Kajimoto Y, Nakano T. Effect of crocetin from Gardenia jasminoides Ellis on sleep: A pilot study. Phytomedicine. 2010;17:84043. https://doi.org/10.1016/j.phymed.2010.03.025

10. Walsh B. History and care of Gardenia plants and Gardenia flowers. [cited 2018 Aug 5]. Available from; https://www.instructables.com/id/History-and-Care-ofGardenia-Plants-and-Gardenia-F/.

11. Pfister $S$, Meyer $P$, Steck $A$, and Pfander $H$. Article isolation and structure elucidation of carotenoid-glycosyl esters in gardenia Fruits (Gardenia jasminoides Ellis) and Saffron (Crocus sativus Linne). J Agric Food Chem. 1996;44(9):2612-15.

12. Inouye $H$, Takeda $Y$, Nishimura $H$. Two new iridoid glucosides from Gardenia jasminoides fruits. Phytochemistry. 1974;13(10):2219-24.

13. Kuo WH, Chou FP, Young SC, Chang YC, Wang CJ. Geniposide activates GSH S-transferase by the induction of GST M1 and GST M2 subunits involving the transcription and phosphorylation of MEK-1 signaling in rat hepatocytes. Toxicol Appl Pharmacol. 2005;208(2):155-62.

14. In-Ah L, Jin Hee L, Nam-In B, Dong-Hyun K. Antihyperlipidemic effect of crocin isolated from the fructus of Gardenia jasminoides and its metabolite crocetin. Biol Pharm Bull. 2005;28(11):2106-10.

15. Thanh QP, François C, Edward F, Van HT, Marie-Rose VC. Antioxidant properties of crocin from Gardenia jasminoides Ellis and study of the reactions of crocin with linoleic acid and crocin with oxygen. J Agric Food Chem. 2000;48(5):145561.

16. 16. Yang $C, H a o ~ Z, X i T$, Can Z, Le C, Ying L, et al. Antioxidant potential of crocins and ethanol extracts of Gardenia jasminoides Ellis and Crocus sativus L. A relationship investigation between antioxidant activity and crocin contents. Food Chemistry. 2008;109(3):484-92.

17. Hye-Jin K, Sanghyun L, Kuk-Hyun S, Byung-Chul K, Chang-Jin L, Eun-Hee P. Geniposide, an anti-angiogenic compound from the fruits of Gardenia jasminoides. Planta Med. 2004;70(5):467-9.
18. Pyeongjae L, Jongseok L, Sang Yoon C, Sang Eun L, Sanghyun L, Dongwook $S$. Geniposide from Gardenia jasminoides attenuates neuronal cell death in oxygen and glucose deprivation-exposed rat hippocampal slice culture. Bio Pharm Bull. 2006;29(1):174-6.

19. Hye-Jin K, Kyung-Hwa L, Hyun-Joo J, Eun-Hee P. Anti-inflammatory evaluation of gardenia extract, geniposide and genipin. J Ethnopharmacol. 2006;103(3):496500

20. $\mathrm{Hu} \mathrm{QH}$, Zhu JX, Ji J, Wei LL, Miao MX, Ji H. Fructus Gardenia Extract ameliorates oxonate-induced hyperuricemia with renal dysfunction in mice by regulating organic ion transporters and mOIT3. Molecules. 2013;18(8):8976-93.

21. Nam $Y$, Lee D. Ameliorating effect of zhizi (Fructus gardeniae) extract and its glycosides on scopolamine-induced memory impairment. J Tradit Chin Med. 2013;33(2):223-7

22. Li W, Li X, Du Q, Li F, Zhu Y, Liu Y, et al. Effect of tongluojiunao injection made from sanqi (Radix Notoginseng) and zhizi (Fructus Gardeniae) on brain microvascular endothelial cells and astrocytes in an in vitro ischemic model. J Tradit Chin Med. 2014;34(6):725-32.

23. Tao $W$, Zhang $H$, Xue $W$, Ren $L$, Xia B, Zhou X, et al. Optimization of supercritical fluid extraction of oil from the fruit of Gardenia jasminoides and its antidepressant activity. Molecules. 2014;19(12):19350-60.

24. Nagata Y, Watanabe T, Nagasaka K, Yamada M, Murai M, Takeuchi S, et al. Total dosage of gardenia fruit used by patients with mesenteric phlebosclerosis. BMC Complement Altern Med. 2016;16:207.

25. Gao L, Zhu BY. The accumulation of crocin and geniposide and transcripts of phytoene synthase during maturation of Gardenia jasminoides fruit. Evid Based Complement Alternat Med. 2013;2013:686351.

26. Xi L, Qian Z, Du P, Fu J. Pharmacokinetic properties of crocin (crocetin digentiobiose ester) following oral administration in rats. Phytomedicine. 2007;14(9):633-6.

27. Choi JY, Pena ID, Choi JH, Yoon SY, Yim DS, LeeYS, et al. Psychopharmacological profile of the water extract of Gardenia jasminoides and its constituents genipin and geniposide, in mice. Biomol Ther. 2008;16(2):118-25.

28. Zhang H, Feng N, XuYT, LiTX, Gao XM, ZhuY, et al. Chemical constituents from the flowers of wild Gardenia jasminoides J. Ellis. Chem Biodivers. 2017;14(5).

29. Morin CM, LeBlanc M, Daley M, Gregoire JP, Merette C. Epidemiology of insomnia: Prevalence, self-help treatments, consultations, and determinants of help-seeking behaviors. Sleep Med. 2006;7(2):123-30.

30. Kyle SD, Morgan K, Espie CA. Insomnia and health-related quality of life. Sleep Med Rev. 2010;14(1):69-82

31. Scott GW, Scott HM, O'Keeffe KM, Gander PH. Insomnia - treatment pathways, costs and quality of life. Cost Eff Resour Alloc. 2011; 9:10.

\section{GRAPHICAL ABSTRACT}

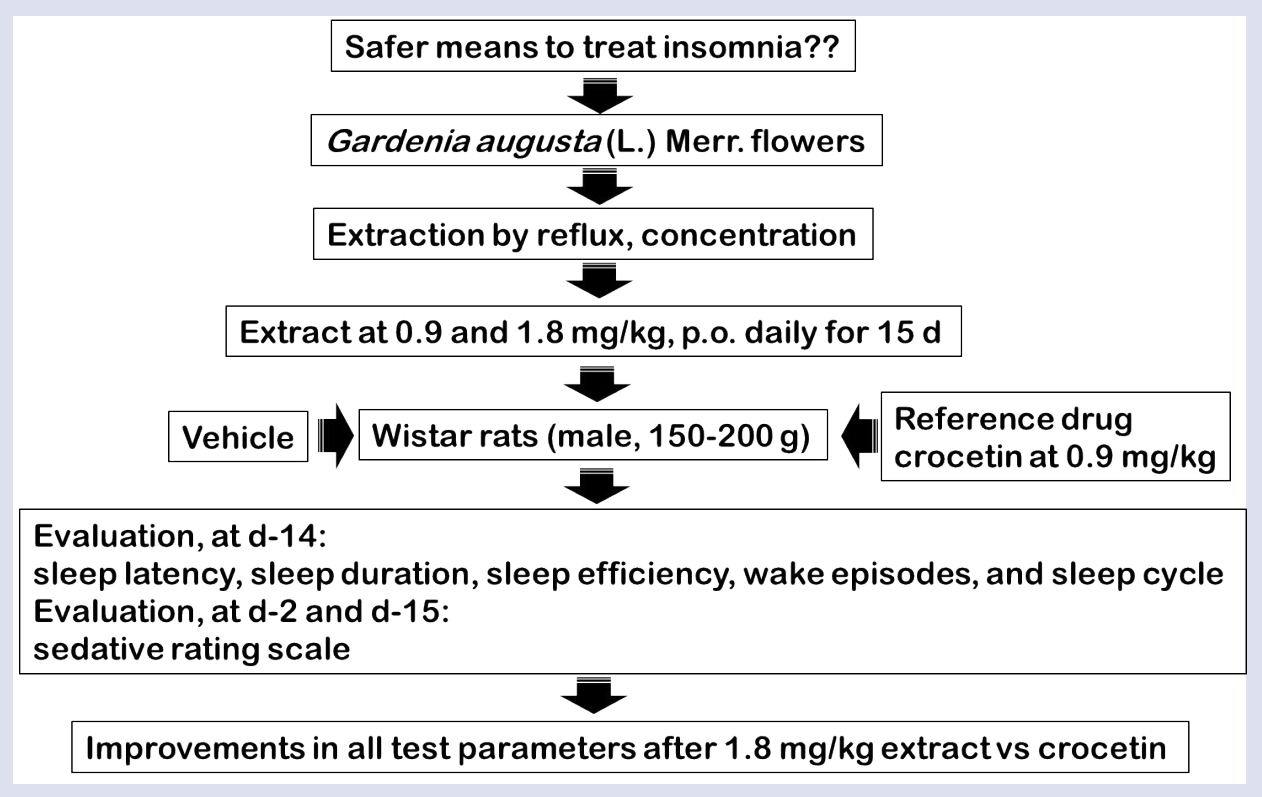




\section{SUMMARY}

This work aimed to investigate the effects Gardenia augusta (L.) Merr. flowers extract in improving sleep quality in rat model. The extract at doses of 0.9 and $1.8 \mathrm{mg} / \mathrm{kg}$ were given orally to male Wistar rats once daily for 15 days. On day 14 of treatment all rats were assessed for several sleep parameters including sleep latency, sleep duration, sleep efficiency, wake episodes, and sleep cycle. In addition, on day-2 and 15, the rats were evaluated for sedative rating scale. The results showed that Gardenia extract at $1.8 \mathrm{mg} / \mathrm{kg}$ improved all test parameters when compared to the reference drug crocetin.

\section{ABOUT AUTHORS}

Kusandar Anggadiredja is currently an associate professor at Department of Pharmacology and Clinical Pharmacy, Institut Teknologi Bandung. His works focus on the research in neuropharmacology.

I Ketut Adnyana is currently a professor at Department of Pharmacology and Clinical Pharmacy, Institut Teknologi Bandung. His works focus on the research in pharmacological activities of natural product-derived drugs.

Ms. Dewi Safitri, Ms. Siti Farah Rahmawati, and Mr. Tomi Hendrayana, faculty members at Department of Pharmacology and Clinical Pharmacy, Institut Teknologi Bandung, are currently pursuing their doctoral degree in the field of pharmacology.

Cite this article: Anggadiredja K, Adnyana IK, Safitri D, Rahmawati SF, Hendrayana T. Ethanol Extract of Gardenia augusta (L.) Merr. Flowers Produces Sleep Improvement in Rat Model. Pharmacog J. 2019;11(6)Suppl:1449-54. 